\title{
Sustainable Development of Pharmaceutical Industry: Balancing Enterprise Innovation with Public Interests
}

\author{
Chunming $\mathrm{Xu}^{1}$, Debao $\mathrm{Zhu}^{2 *}$ \\ ${ }^{1}$ Law School, Shanghai University, Shanghai 200444, China \\ ${ }^{2}$ School of Management, Shanghai University, Shanghai 200444, China
}

Corresponding Author Email: zhudebao@shu.edu.cn

https://doi.org/10.18280/ijsdp.150506

Received: 17 January 2020

Accepted: 6 April 2020

\section{Keywords:}

pharmaceutical industry, innovation incentive, public interests, noncooperative game

\begin{abstract}
In the pharmaceutical industry, the conflicts mainly exist between innovator drug enterprise and generic drug enterprise, and between enterprises and patients. The first kind of conflicts are about technical innovation, and the latter kind are about public interests. Based on noncooperative game model and theory, this paper analyzes the profit distribution between innovator drug enterprise and generic drug enterprise, highlighting the necessity of patent system in incentivizing the innovation of pharmaceutical enterprises and the problem of high drug prices induced by patent monopoly. Then, the excess profits tax (EPT) was introduced to regulate drug prices and safeguard the medical right of the patients. Further, the authors examined the decision-making motives of pharmaceutical enterprises in the game, and the effect mechanism of taxation. The results show that the patent system should protect both innovator drug enterprise and generic drug enterprise (as the secondary innovator); the system should be supported with taxation to regulate the market prices of drugs, such as to balance innovation with public interests and promote the sustainable development of technology and economy.
\end{abstract}

\section{INTRODUCTION}

The world today is threatened by various kinds of epidemic diseases. Breakthroughs in drug technology are urgently needed to cope with these diseases [1]. To promote technical innovation, it is critical to protect drug research and development (R\&D) with patent system. Despite the long cycle and high cost of drug development, new drugs can be imitated very easily. If the rights of innovators are not strictly protected, the pharmaceutical industry will fall victim to the tragedy of the commons.

The patent system grants patent rights to innovators, providing them with the legal basis to file infringement lawsuits against imitators. In this way, the interests of patentees could be safeguarded well. However, patent rights are monopolistic in time and space, which inevitably makes the prices of patented drugs much higher than their marginal costs. The soaring prices will harm the rights and interests of patients, especially those in developing countries. Since drugs were covered by patent law, two major problems have surfaced in the pharmaceutical industry: How to balance the interests between innovators and imitators with the patent system? How to resolve the conflict of interests between enterprises and the public?

In the pharmaceutical industry, the innovators and imitators are respectively innovator drug enterprises and generic drug enterprises. The relative position of the two kinds of enterprises are dynamically changing. The R\&D of each drug takes more than a decade, and generates hundreds of patents $[2,3]$. The generic drug enterprises could legally acquire patented techniques through licensing and cross-licensing, by implementing peripheral patent strategy and patent evasion strategy.

For example, Japanese enterprises often buy patented techniques through licensing in the early stage of drug development, and then invest actively in drug R\&D and sales. Chinese enterprises tend to increase their bargaining power by optimizing peripheral techniques like preparations and secondary formulations, or by establishing economies of scale and implementing mergers and acquisitions [4-6].

If a generic drug enterprise competes by applying for peripheral patents, the patents it holds usually complement the patents of the innovator drug enterprise. To avoid the risk of infringement, the generic drug enterprise must acquire the corresponding licenses. The existing studies on patent licensing generally try to optimize the licensing fee under the maximal corporate profits. Meanwhile, some scholars have discussed how patent licensing is affected by enterprise strength, market competition, and current policies [7, 8].

China has one of the largest generic drug industries in the world. The medical burden of Chinese patients is greatly lighted by the many generic drug enterprises. From the original intention of the patent system, the emergence of generic drug enterprises is bound to dampen the innovation of innovator drug enterprises. However, the medical right of the public will be damaged, if the generic drug development is strictly restricted by the patent system [9, 10]. Every government is faced with the inconvenient task to strike a balance between innovation and imitation, that is, to promote innovation while easing the public medical burden, and promote the sustainable development of the pharmaceutical industry. 
Faced with this arduous task, the governments around the world have attempted to reduce the medical burden by means of drug price regulation or weakening patent protection. After strict cost-profit analysis, Britain rolled out the Pharmaceutical Price Regulatory Scheme (PPRS), which directly limits the profits of pharmaceutical enterprises [11]. For the public good, the Indian government refuses to grant patents to medical inventions, opposes profiteering at the cost of life and health rights, and takes compulsory licensing to provide the public with reliable and stable drug prices $[12,13]$. China, Brazil, Mexico, and South Africa all rely on compulsory licensing to guarantee the drug accessibility. That is why many generic drug enterprises exist in these countries. Albeit the unstable quality, the generic drugs produced in these countries are much cheaper than patented drugs, and thus very competitive in the market [14-16].

In addition, Nguyena et al. [17] held that, under a certain market pattern, the profits of drug enterprises can be increased through parallel import from developed countries to developing countries. Many developed countries have tolerated parallel import to attract advanced techniques and products from foreign countries [12, 17, 18]. Currently, parallel import is mainly backed up by two theories: exhaustion of rights [19, 20] and implied license [21, 22]. Admittedly, compulsory licensing and parallel import can both alleviate the public health crisis. But the benefit comes at the cost of the interests of innovators, and hinders innovation in the pharmaceutical industry. In the long run, the two measures will harm the long-term interests of patients.

The above regulation policies on drug prices demonstrate that the patent system, which seems to protect private rights, inherently protects the public rights [21]. In a fully free market, it is difficult to maximize public interests. Thus, the government is obliged to protect innovation, promote imitation, and ease the medical burden of the public.

From the perspective of the government, this paper explores the competition and profit distribution between the innovator drug enterprise and the generic drug enterprise in the pharmaceutical industry. Besides, taxation was coupled with the patent system to encourage innovation and protect public interests. The main research contents are as follows:

(1) The non-cooperative game was introduced to discuss the profit distribution in cross-licensing between innovator drug enterprise and generic drug enterprise at different patent shares. Then, taxation was added to the game model to provide a scheme that protect public interests.

(2) The decision-making motives of competing pharmaceutical enterprises were analyzed, and a policy environment was designed to balance innovation and public interests and to promote the sustainability of the pharmaceutical industry.

The remainder of this paper is organized as follows: Section 2 introduces the research method of non-cooperative game and set up a game model; Section 3 analyzes the model results in details; Section 4 puts forward the conclusions and looks forward to the future research.

\section{METHODOLOGY}

From project initiation to hitting the market, the $R \& D$ of a new drug involves an average of more than 100 patents, which are often held by different enterprises. The patents owned by different enterprises usually complement each other. Crosslicensing between these enterprises is necessary for them to make profits:

$$
A \stackrel{\text { Licensing fee }}{\rightleftharpoons} B
$$

For simplicity, it is assumed that a market has two enterprises. The one with greater patent shares is the innovator drug enterprise, denoted as A; the one with fewer patent shares is the generic drug enterprise, denoted as B. The noncooperative game model was introduced, whose parameters are listed in Table 1 below.

Table 1. Model parameters

\begin{tabular}{|c|c|c|c|}
\hline Name & Meaning & Name & Meaning \\
\hline$\eta_{i}$ & The patent share of A or $\mathrm{B}, i=1,2$ & $E_{1}{ }^{\mathrm{i}}$ & The gross yield of A or $\mathrm{B}, i=1,2$ \\
\hline$\alpha_{i}$ & The premium ratio of drug produced by A or $\mathrm{B}, i=1,2$ & $E_{2}{ }^{\mathrm{i}}$ & $\begin{array}{l}\text { The excessive profit of A or B subject to excess } \\
\text { profits tax (EPT), } i=1,2\end{array}$ \\
\hline$\omega_{i}$ & $\begin{array}{l}\text { The licensing fee as a proportion of profit per unit of drug } \\
\text { paid by A or B to the other party, } i=1,2\end{array}$ & $y_{i}$ & The market share of A or $\mathrm{B}, i=1,2$ \\
\hline$d_{i}$ & The slack term of A or B in license negotiation, $i=1,2$ & $c_{i}$ & $\begin{array}{l}\text { The cost per unit of drug, including the R\&D cost, } \\
\text { of A or } \mathrm{B}, i=1,2\end{array}$ \\
\hline$F_{i}$ & The licensing fee paid by A or B to the other party, $i=1,2$ & $s$ & Patient satisfaction $(\%)$ \\
\hline$r_{i}$ & \multicolumn{3}{|c|}{ The R\&D cost of $\mathrm{A}$ or $\mathrm{B}, i=1,2$} \\
\hline
\end{tabular}

Let $\eta_{1}$ and $\eta_{2}$ be the patent share of $\mathrm{A}$ and $\mathrm{B}$, respectively. Since the patents of $\mathrm{A}$ and $\mathrm{B}$ complement each other, then:

$$
\eta_{1}+\eta_{2}=1
$$

where, $0 \leq \eta_{1} \leq 1 ; 0 \leq \eta_{2} \leq 1$.

Before selling a drug, A must acquire the license from $\mathrm{B}$ and pay the latter the licensing fee. After selling a unit of drug, A should transfer a proportion $\omega_{1}$ of the profit to B. Similarly, after selling a unit of drug, B should transfer a proportion $\omega_{2}$ of the profit to A. These proportions depend on the patent shares of A and B. The lower the patent share, the higher the proportion of the profit transfer:

$$
0 \leq \eta_{2}\left(1-d_{1}\right) \leq \omega_{1} \leq \eta_{2}\left(1+d_{1}\right) \leq 1
$$

$$
0 \leq \eta_{1}\left(1-d_{2}\right) \leq \omega_{2} \leq \eta_{1}\left(1+d_{2}\right) \leq 1
$$

where, $0 \leq \omega_{1} ; \omega_{2} \leq 1 ; \eta_{2}\left(1-d_{1}\right)$ and $\eta_{2}\left(1+d_{1}\right)$ are the upper and lower limits of the licensing fee receivable by A, respectively; $d_{1}$ is the slack term of $\mathrm{A}$ in license negotiation; $\eta_{1}\left(1-d_{2}\right)$ and $\eta_{1}\left(1+d_{2}\right)$ are the upper and lower limits of the licensing fee receivable by $\mathrm{B}$, respectively; $d_{2}$ is the slack term of $\mathrm{B}$ in license negotiation; $d_{1}=d_{2}=20 \%$.

Then, the licensing fee paid by A to B and that paid by B to A can be respectively expressed as: 


$$
\begin{aligned}
& F_{1}=\left(\alpha_{1}-1\right) \cdot c_{1} \cdot \omega_{1} \cdot y_{1} \\
& F_{2=}\left(\alpha_{2}-1\right) \cdot c_{2} \cdot \omega_{2} \cdot y_{2}
\end{aligned}
$$

Let $r_{1}$ and $r_{2}$ be the $\mathrm{R} \& \mathrm{D}$ costs of $\mathrm{A}$ and $\mathrm{B}$, respectively. Then, the profits of A and B can be calculated by subtracting production cost, licensing fee and $\mathrm{R} \& \mathrm{D}$ cost from the total sales:

$$
\begin{gathered}
E_{1}^{1}=\left(\alpha_{1}-1\right) \cdot\left(1-\omega_{1}\right) \cdot c_{1} \cdot y_{1}-r_{1} \\
E_{1}^{2}=\left(\alpha_{2}-1\right) \cdot\left(1-\omega_{2}\right) \cdot c_{2} \cdot y_{2}-r_{2}
\end{gathered}
$$

Meanwhile, A and B need to pay an EPT of $E_{1}^{1} \cdot t$ and $E_{2}^{2} \cdot$ $t$, respectively:

$$
E_{1}^{1,2}= \begin{cases}0, & \text { other conditions } \\ E_{1}^{1,2}-E_{0}, & \text { if } E_{1}^{1,2} \geq E_{0} \text { and } \alpha \geq 2\end{cases}
$$

To sum up, the profits of $\mathrm{A}$ and $\mathrm{B}$ can be respectively described as:

$$
\begin{gathered}
E_{1}^{1}-E_{2}^{1} \cdot t=\left(\alpha_{1}-1\right) \cdot\left(1-\omega_{1}\right) \cdot c_{1} \cdot y_{1}-r_{1}-E_{2}^{1} \cdot t \\
E_{1}^{2}-E_{2}^{2} \cdot t=\left(\alpha_{2}-1\right) \cdot\left(1-\omega_{2}\right) \cdot c_{2} \cdot y_{2}-r_{2}-E_{2}^{2} \cdot t
\end{gathered}
$$

In addition, the market share of an enterprise will decline, as its premium ratio continues to rise. Suppose A and B produce drugs of the same quality and at the same cost. For simplicity, it is further assumed that the marginal production costs of A and B are zero. Then, the correlation between premium ratio and market share can be described as:

$$
\begin{gathered}
y_{1}=g\left(\alpha_{1}, \eta_{1}\right)= \begin{cases}\alpha_{2} / \alpha_{1} \cdot \eta_{1} y_{\text {max }} & , \alpha_{1} \leq \alpha_{0} \\
\alpha_{2} / \alpha_{1} \cdot \eta_{1} \frac{y_{\text {max }}}{\alpha_{1}-\alpha_{0}+1}, & \alpha_{1}>\alpha_{0}\end{cases} \\
y_{2}=g\left(\alpha_{2}, \eta_{2}\right)= \begin{cases}\alpha_{1} / \alpha_{2} \cdot \eta_{2} y_{\text {max }} & , \alpha_{2} \leq \alpha_{0} \\
\alpha_{1} / \alpha_{2} \cdot \eta_{2} \frac{y_{\text {max }}}{\alpha_{2}-\alpha_{0}+1}, & \alpha_{2}>\alpha_{0}\end{cases}
\end{gathered}
$$

If the premium ratio grows to a critical value, the drug price will be unaffordable, forcing some patients to resort to other ways of treatment. The critical premium ratio can be defined as:

$$
\sum_{i=1}^{2} y_{i} \leq y_{\max }
$$

Taxation is an instrument for the government to regulate drug prices. Here, the patient satisfaction function $s$ is introduced to quantify the effect of taxation, which imposes an EPT of $20 \%$ on the excessive profit of drugs. The patient satisfaction with A or B can be computed by:

$$
s_{i}=\frac{1}{1+e^{\left(\frac{\alpha_{i}}{10}-2\right)}}, \quad i=1,2
$$

The patient satisfaction of A and B can be obtained by:

$$
s=\eta_{1} s_{1}+\eta_{2} s_{2}
$$

If drug prices are effectively controlled, patient satisfaction will increase; otherwise, patient satisfaction will decrease.

As a party of the game, A aims to maximize its profit. According to the premium ratio $\alpha_{1}$ of $\mathrm{A}$, the licensing fee as a proportion $\omega_{2}$ of profit per unit of drug paid by B, and the market share $y_{1}$ of $\mathrm{A}$, the following optimization model can be established for $\mathrm{A}$ :

$$
\begin{aligned}
& \max _{\alpha_{1}, \omega_{2}, y_{1}}\left(\alpha_{1}-1\right) \cdot\left(1-\omega_{1}\right) \cdot c_{1} \cdot y_{1}-r_{1}-E_{2}^{1} \cdot t \\
& \text { s.t. } \\
& \sum_{i=1}^{2} y_{i} \leq y_{\max }, \\
& y_{1}=g\left(\alpha_{1}, \eta_{1}\right) \\
& =\left\{\begin{array}{l}
\alpha_{2} / \alpha_{1} \cdot \eta_{1} y_{\max } \quad, \alpha_{1} \leq \alpha_{0} \\
\alpha_{2} / \alpha_{1} \cdot \eta_{1} \frac{y_{\max }}{\alpha_{1}-\alpha_{0}+1}, \alpha_{1}>\alpha_{0}
\end{array},\right. \\
& E_{2}^{1}=\left\{\begin{array}{l}
0, \quad \text { other conditions } \\
E_{2}^{1}-E_{0}, \quad \text { if } E_{1}^{1} \geq E_{0} \text { and } \alpha_{1} \geq 2
\end{array},\right. \\
& 0 \leq \eta_{1}\left(1-d_{2}\right) \leq \omega_{2} \leq \eta_{1}\left(1+d_{2}\right) \leq 1 .
\end{aligned}
$$

Similarly, the optimization model for B can be established as:

$$
\begin{aligned}
& \max _{\alpha_{2}, \omega_{1}, y_{2}}\left(\alpha_{2}-1\right) \cdot\left(1-\omega_{2}\right) \cdot c_{2} \cdot y_{2}-r_{2}-E_{2}^{2} \cdot t \\
& \text { s.t. } \\
& \sum_{i=1}^{2} y_{i} \leq y_{\max }, \\
& y_{2}=g\left(\alpha_{2}, \eta_{2}\right) \\
& =\left\{\begin{array}{l}
\alpha_{1} / \alpha_{2} \cdot \eta_{2} y_{\text {max }} \quad, \alpha_{2} \leq \alpha_{0} \\
\alpha_{1} / \alpha_{2} \cdot \eta_{2} \frac{y_{\max }}{\alpha_{2}-\alpha_{0}+1}, \alpha_{2}>\alpha_{0}
\end{array},\right. \\
& E_{2}^{2}=\left\{\begin{array}{l}
0, \\
E_{2}^{2}-E_{0}, \quad \text { if } E_{1}^{2} \geq E_{0} \text { and } \alpha_{2} \geq 2
\end{array}\right. \\
& 0 \leq \eta_{2}\left(1-d_{1}\right) \leq \omega_{1} \leq \eta_{2}\left(1+d_{1}\right) \leq 1 .
\end{aligned}
$$

Then, models I and II were solved by genetic algorithm (GA) on MATLAB 2016a.

\section{RESULTS AND DISCUSSION}

\subsection{Profit analysis}

In cross-licensing, A and B each holds part of the relevant patents, and treats its patent share as a bargaining chip for profit distribution. The two enterprises are competitors in the game.

\subsubsection{Profits without taxation}

Figure 1 shows the relationship between A's profit and B's profit in the absence of taxation. It can be seen that the profits 
of the two enterprises conflicted with each other, and A's profit was always greater than B's profit, because A has absolute technical advantage in our game model.

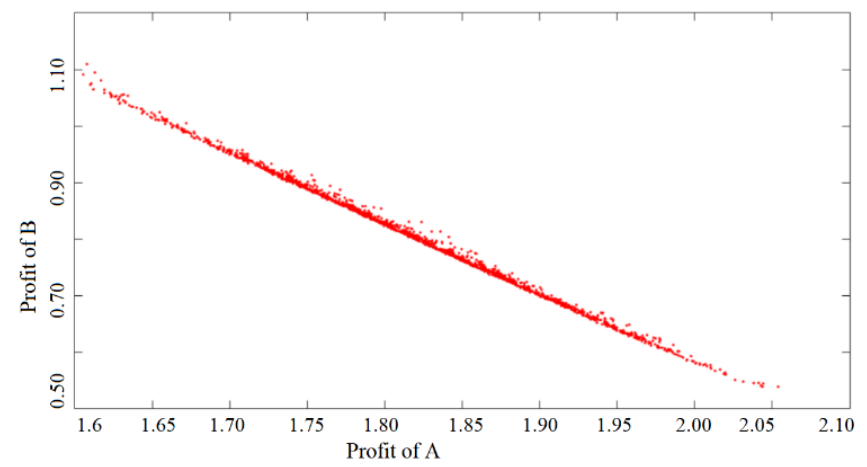

Figure 1. The relationship between A's profit and B's profit in the absence of taxation

In fact, the above situation will not occur unless A and B differ sharply in resource strength. If an enterprise is relatively weak, it is unwise to license out its technology, especially to a competitor. The licensing will easily cause leakage of technical information, and weaken the competitive edge of the enterprise.

On the contrary, if an enterprise is relatively strong, it is inclined to license out its technology, such as to quickly occupy the market and promote its patented technology into an industry standard. Apart from license income, the licensing will prevent competitors from entering the market. That is, technical licensing is more popular in a competitive landscape with less pressure.

In our game model, most patents are possessed by A, and only a small portion is held by $\mathrm{B}$. Even if $\mathrm{B}$ is in a passive state, it is a reasonable choice to actively promote licensing in order to industrialize its technology.

Note that the technical assets of a medium-sized enterprise are supported by production resources or sales channels. If it is under rapid growth, the enterprise is often reluctant to license out its technology. This situation is excluded in our model by the large strength gap between $\mathrm{A}$ and $\mathrm{B}$, making the game result more reasonable.

In other words, an enterprise possessing core or basic patents, e.g. A, prefers to license its patents to enterprises in another field or weak enterprises in the same field, after evaluating the R\&D level and supporting assets of its peers and considering the threats from its competitors. The purpose of the licensing is to maintain the monopoly advantage and impede the growth of potential competitors.

\subsubsection{Profits with taxation}

Figure 2 shows the relationship between A's profit and tax revenue. Figure 3 shows the relationship between A's profit and B's profit in the presence of taxation. Obviously, the relationship changed from negative correlation to positive correlation. This is because the conflict between profit and taxation becomes the main influencing factor in the game.

When the government uses coercive force of the state to regulate drug prices, its objective goes against the interests of $\mathrm{A}$ and $\mathrm{B}$. In this case, the two enterprises will coordinate with each other in drug pricing. The profit-seeking enterprises tend to mark up drug prices and expand the market. However, the tax burden will also grow, if the drug prices rose to a critical level. In the presence of the EPT, increasing the premium ratio will lead to a greater tax burden and a higher risk of losing market shares, despite bringing more profit.

It is apparent that high tax rate and high consumption can increase tax revenue. However, a high tax rate will greatly suppress enterprise profit, making them less willing and able to implement follow-up R\&D. In this case, the laws of market will be disrupted, and the economic operation will be distorted, which indirectly harms the public interests.

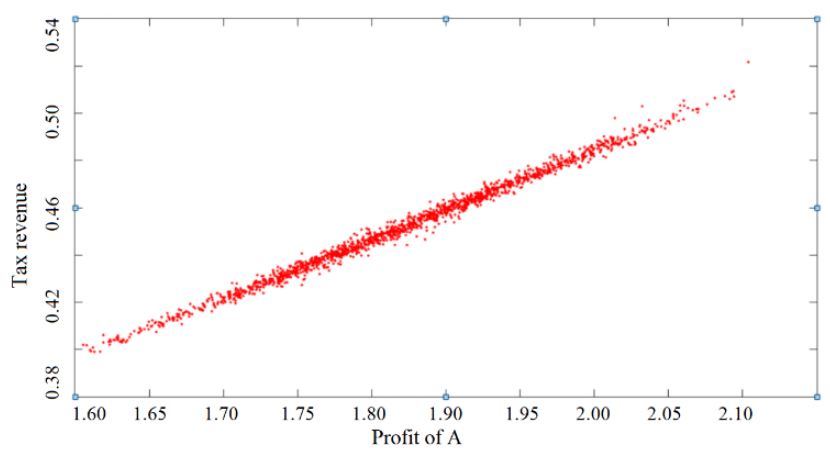

Figure 2. The relationship between A's profit and tax revenue

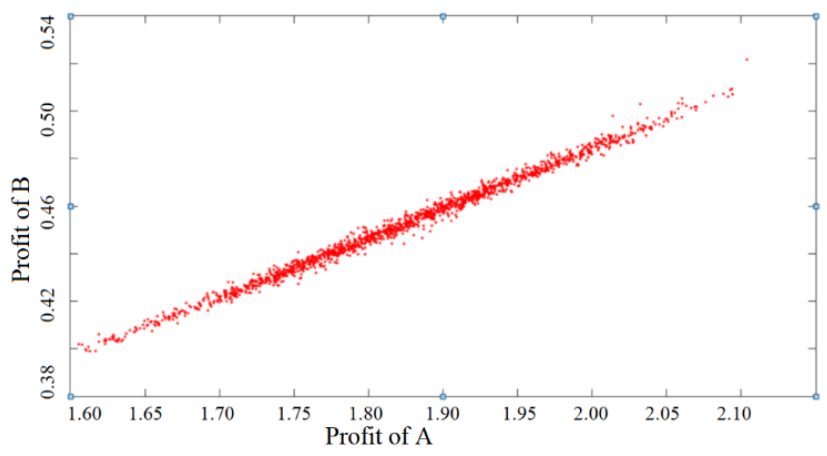

Figure 3. The relationship between A's profit and B's profit in the presence of taxation

\subsection{Decision-making motives in competition}

This subsection analyzes the decision-making motives of the innovator drug enterprise and the generic drug enterprise in the game. Overall, the decision-making is affected by internal and external factors.

The internal factors mainly refer to resource strength of enterprises, which determines the game result. In our model, the resource strength is quantified by the patent share. Based on patent share, the profit distribution pattern between the two enterprises was discussed. This pattern greatly affects the rational choice of both parties in the game.

External factors mainly refer to the supply and demand in the market, the patent system in specific time and space, and the requirements of laws and regulations. In our model, external factors include the patent system for drugs and the EPT. Being the environmental background, these external factors define the direction of the entire industry.

To be specific, resource strength mainly involves financial strength, human resources, and management resources. For an enterprise, its resource strength determines the industrial status and decisions. Large enterprises like innovator drug enterprises (e.g. A) have sufficient financial strength to apply 
for, operate and implement patents. As a result, large enterprises wish to maximize its technical advantages and adopt the exclusive patent strategy.

Meanwhile, generic drug enterprises, generally lacking funds, market recognition and marketing power, prefer to implement peripheral patent strategy, which gives them the same bargaining power as large enterprises. By this strategy, generic drug enterprises could obtain critical assets through cooperation and licensing, and legally attract investment.

Although large enterprises have first-mover advantage, the patent rights are unlikely to concentrate in the pocket of one enterprise only, due to the severe technology spillovers in the pharmaceutical industry. As a result, it is very difficult to realize the exclusive patent strategy. Then, the development of an enterprise not only relies on its own technical innovation, but also dependent on the R\&D results of its peers. The enterprise can either acquire license legally by paying the licensing fee, or steal the patented technology from others illegally.

Therefore, enterprises tend to invest more in R\&D and increase patent output, when the patent system is complete in the market and the patent protection is enforced forcefully. In the drug market, the relevant patents of the same product are usually held separately by multiple enterprises. To occupy the market and industrialize the technology, the patent owners are very likely to cooperate with each other through crosslicensing.

In addition, as more competitors enter the market, the enterprise will witness a decline in influence and a growth in profit risk. At this time, the enterprise will choose to license out its technology. Pursuing the maximal interests, large enterprises often combine exclusive patent strategy with blocking strategy; small and medium-sized enterprises would integrate defensive patent strategy with the utilization of expired patents, gaining the bargaining power for the licensing negotiation before product industrialization.

\subsection{Effect mechanism of incentive policies}

The above analysis shows that effective patent protection is the precondition for incentivizing technical innovation, and reasonable taxation can regulate drug prices to a certain extent. These empirical results provide the government with the directions to guide the pharmaceutical industry. To prevent risk and improve taxation, it is important to fully understand the effect mechanism of incentive policies on drug innovation.

Firstly, the innovation activities in the pharmaceutical industry need incentives to offset the high innovation risks, which arise from the various uncertainties in the decade-long innovation cycle (from $R \& D$, clinical testing to hitting the market). Then, how does the patent system guide pharmaceutical enterprises to overcome the high risks?

The prospect theory goes that our attitude towards risk depends on the preset reference point for decision-making in our mind. If the result is higher than the reference point, the decision-maker will be risk-averse; if the result is below the reference point, the decision-maker will be risk-taking. In other words, our decision-making is determined by the gap between the result and the expectation, rather than the result itself. In the pharmaceutical industry, technical innovation is highly risky and investment-demanding. The innovator drug enterprise, as the main innovation subject, must weigh the result against the reference point, when deciding whether to invest in the R\&D.
According to the analysis of prospect theory, the innovator drug enterprise should be promised a high return (usually monopoly profit) in order to implement drug innovations. The promise will elevate the reference point in the mind of the decision-makers, encouraging them to take the risk of technical innovation. Following this train of thought, the government should lay down a forceful policy on patent protection for drug innovations. The policy caters to the mindset of pharmaceutical enterprises: Drug technologies, which are not highly complex, could be imitated at a low cost; rather than keep technologies as secrets, pharmaceutical enterprises tend to protect innovations by patent disclosure.

The prospect theory points out that, to encourage innovation, monopoly profit should be awarded to the innovation subject. However, it takes a long cycle to develop a new drug. The patent of a new drug covers various issues, including active ingredients, compositions, crystal forms, processes, preparations, and new uses. The final drug on the market is not entirely the original invention, but the result of one or multiple improvements. That is, generic drug enterprises also play an important role in drug $\mathrm{R} \& \mathrm{D}$ activities. Both the original innovation and the subsequent improvements should be recognized. The secondary innovation by generic drug enterprises is not possible if the original inventors refuse to distribute profits with them.

However, the profit distribution between innovator and generic drug enterprises will kick off the innovation competition in the drug market, resulting in division of patent rights. For example, the drug patents are possessed by different enterprises, whose possessions complement each other. Fortunately, the separated yet complementary patents could be merged through cross-licensing and other methods, enabling the industrial application of new drugs. Despite its high cost of search and negotiation, the merge of patents is better than oligopoly or stagnation of innovation.

The key to the merge is that the divided patent rights must be complementary. The two enterprises, which hold different patents of the same product, must integrate their patents to successfully launch the product without the risk of infringement. In this way, the patent rights are dispersed, and the subsequent merge is simplified, making it possible to promote innovation and curb oligopoly. Under this premise, even if the innovator drug enterprise makes a higher investment, it is very likely to cooperate with the generic drug enterprise through patent licensing.

This is like the wise pig game, in which the profit distribution determines the rational choice of the two parties. The innovator and generic drug enterprises are comparable to the larger and smaller pigs, respectively, while technical innovation is similar to the control button, which brings benefits to the enterprises. The innovator drug enterprise has sufficient funds, high productivity, and strong innovation ability. Once a new product is launched, the enterprise can occupy the market and obtain high profit. The best choice for the generic drug enterprise is to implement peripheral patent strategy after large enterprises make technical innovations. Following this strategy, the generic drug enterprise can acquire more bargaining power, seize greater market shares, and profit from the technical innovations of large enterprises.

The above patent system can promote innovation, but cannot effectively regulate drug prices. Both innovator and generic drug enterprises are profit-oriented, and take a completely opposite market stance with patients. With the monopoly power granted by the patent law, the pharmaceutical 
enterprises will definitely increase drug prices. Some theories recommend these enterprises to implement differential pricing for different patient groups. But monopolists usually decide to do the otherwise: low-price drugs could gnaw away the market and drag down the price of high-price drug; providing medicines to low- and middle-income groups requires additional investment in production capacity with uncertain rate of return. Therefore, the government must step forward to balance innovation with public interests.

The most effective balancing strategy is to couple the patent system with a reasonable tax burden. In our model, the EPT is added to tax the production factors like the income of pharmaceutical enterprises. This taxation method is efficient and easy to implement. The EPT policy reflects the following ideas: With the aim to maximize public interests, the government should forcefully intervene in market failures, and correct the public losses caused by monopoly, while ensuring that patent owners receive sufficient incentives. Of course, the government must set the tax rate carefully to avoid one-sided justice. The EPT policy should protect the vulnerable group of patients, and also safeguard the private patent rights of innovators. Under a reasonable tax policy, the able will receive more profit, and technical and economic development will be more sustainable.

\section{CONCLUSIONS}

This paper attempts to balance the technical innovation of pharmaceutical enterprises and the public interests, and guide the healthy development of the pharmaceutical industry. Specifically, the game between innovator and generic drug enterprises, which are the innovation subjects in the pharmaceutical industry, was discussed under the patent system. A non-cooperative game model was constructed to analyze the profit distribution between innovator and generic drug enterprises. Further, the EPT-related parameters were included in the model to explore the effects of taxation on drug prices. The main conclusions are as follows:

The game result is affected by the resource strength of each enterprise and the policy environment. The resource strength determines the final pattern of profit distribution, while the policy environment defines the trend of the entire industry. The government could promote enterprise innovation through the patent system, and regulate the drug prices through taxation.

The patent system that incentivizes innovation should protect the original innovation of the innovator drug enterprise, and also guarantee the improvements by the generic drug enterprise. In this way, the patent system could adapt to the cumulative innovation process in the pharmaceutical industry, promoting the common development of innovation and generic drug enterprises.

The patent system, which promises monopoly profit to pharmaceutical enterprises, is bound to push up the drug prices. To regulate drug prices, the government needs to tax the sales income of pharmaceutical enterprises with the EPT, which is efficient and easy to implement. However, an excessively high EPT will make the enterprises reluctant to pursue innovation, and indirectly harm the public interests. As a result, the tax rate must be designed carefully to balance innovation with public interests, and promote the sustainability of technology and economy in the pharmaceutical industry.
To simply calculation, the EPT rate in our model was assumed as fixed. For the lack of space, only 2 pharmaceutical enterprises are discussed in this research. The future research will explore more complex tax models and consider the competition between multiple enterprises, and further adapt the game model to the reality.

\section{REFERENCES}

[1] Wang, C., Horby, P.W., Hayden, F.G., Gao, G.F. (2020). A novel coronavirus outbreak of global health concern. The Lancet, 395(10223): 470-473. https://doi.org/10.1016/S0140-6736(20)30185-9

[2] Von Graevenitz, G., Wagner, S., Harhoff, D. (2013). Incidence and growth of patent thickets: The impact of technological opportunities and complexity. The Journal of Industrial Economics, 61(3): 521-563. https://doi.org/10.1111/joie.12032

[3] Smith, R.D., Correa, C., Oh, C. (2009). Trade, TRIPS, and pharmaceuticals. The Lancet, 373(9664): 684-691. https://doi.org/10.1016/S0140-6736(08)61779-1

[4] Mahlich, J.C., Roediger-Schluga, T. (2006). The determinants of pharmaceutical R\&D expenditures: evidence from Japan. Review of Industrial Organization, 28(2): 145-164. https://doi.org/10.1007/s11151-006$0010-\mathrm{z}$

[5] Liu, C., Constantinides, P.P., Li, Y. (2014). Research and development in drug innovation: reflections from the 2013 bioeconomy conference in China, lessons learned and future perspectives. Acta Pharmaceutica Sinica B, 4(2):

112-119. https://doi.org/10.1016/j.apsb.2014.01.002

[6] Bao, L. (2007). The competitive strategy for imitative innovation and generic drug. Science and China Youth Technology, (12): 8 .

[7] Saracho, A.I. (2002). Patent licensing under strategic delegation. Journal of Economics \& Management Strategy, 11(2): 225-251. https://doi.org/10.1111/j.14309134.2002.00225.x

[8] Saracho, A.I. (2005). The relationship between patent licensing and competitive behavior. The Manchester School, 73(5): 563-581. https://doi.org/10.1111/j.14679957.2005.00464.x

[9] Sun, Q., Santoro, M.A., Meng, Q., Liu, C., Eggleston, K. (2008). Pharmaceutical policy in China. Health Affairs, 27(4): 1042-1050. https://doi.org/10.1377/hlthaff.27.4.1042

[10] Zeng, W. (2013). A price and use comparison of generic versus originator cardiovascular medicines: A hospital study in Chongqing, China. BMC health services research, 13(1): 390. https://doi.org/10.1186/1472-696313-390

[11] Webb, D.J., Walker, A. (2007). Value-based pricing of drugs in the UK. Lancet, 369(9571): 1415-1416. http://www.thelancet.com/journals/lancet/issue/current? tab $=$ past.

[12] Bond, E., Saggi, K. (2019). Price controls versus compulsory licensing: effects on patent-holders and consumers. The WTO and Economic Development, 303. http://www.accessecon.com/pubs/VUECON/VUECON17-00013.pdf.

[13] Dean, E.B. (2017). Who benefits from pharmaceutical price ceilings. Evidence from India. 
[14] Chaudhuri, S. (2005). Indian pharmaceutical companies and accessibility of drugs under TRIPS. In Commercialization of Health Care, 155-169. https://doi.org/10.1057/9780230523616 10

[15] Brekke, K.R., Holmås, T.H., Straume, O.R. (2015). Price regulation and parallel imports of pharmaceuticals. Journal of Public Economics, 129: 92-105. https://doi.org/10.1016/j.jpubeco.2015.08.002

[16] Hu, J.X. (2016). On the Construction of Patent License of Right System in China. Intellectual Property, (6): 12.

[17] Nguyena, X., Chaoa, C.C., Hwangb, H. (2016). NorthSouth parallel import, trade liberalization and optimal taxation.

[18] Vogler, S., Leopold, C., Zimmermann, N., Habl, C., de Joncheere, K. (2014). The Pharmaceutical Pricing and Reimbursement Information (PPRI) initiativeExperiences from engaging with pharmaceutical policy makers. Health Policy and Technology, 3(2): 139-148. https://doi.org/10.1016/j.hlpt.2014.01.001

[19] Danzon, P.M. (2018). Differential pricing of pharmaceuticals: theory, evidence and emerging issues. PharmacoEconomics, 36(12): 1395-1405. https://doi.org/10.1007/s40273-018-0696-4

[20] Ramsey, F.P. (1927). A contribution to the theory of taxation. The Economic Journal, 37(145): 47-61. https://doi.org/10.2307/2222721

[21] Lai, J.C. (2018). Exclusive rights of patent owners versus rights of chattel owners: The implied license approach. Oxford University Commonwealth Law Journal, 18(2): 99-122.

https://doi.org/10.1080/14729342.2018.1530862

[22] La Belle, M.M. (2012). Patent Law as Public Law. Geo. Mason L. Rev., 20: 41. 